\title{
Publisher Correction: Predicting unpredictability
}

Steven J. Davis

Correction to: Nature Energy https://doi.org/10.1038/s41560-018-0127-y, published online 26 March 2018.

In this News \& Views article originally published, the wrong graph was used for panel $\mathbf{b}$ of Fig. 1, and the numbers on the $y$ axes of panels a and $\mathbf{c}$ were incorrect; the original and corrected Fig. 1 is shown below. This has now been corrected in all versions of the News \& Views.

Original

a

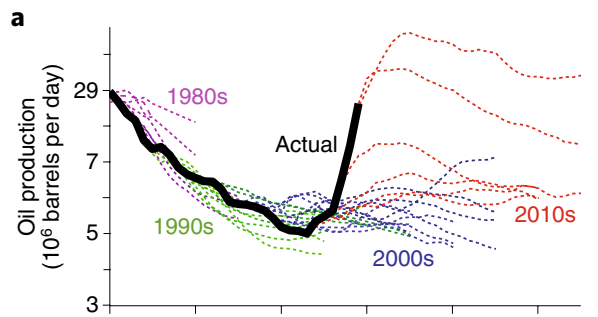

b

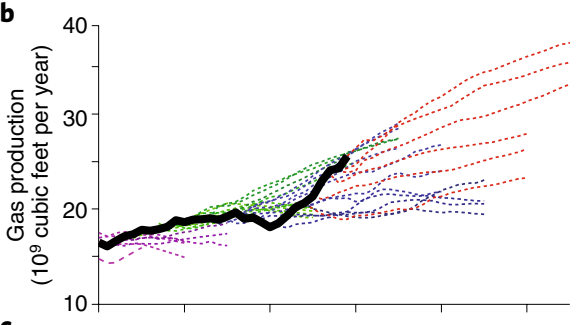

c

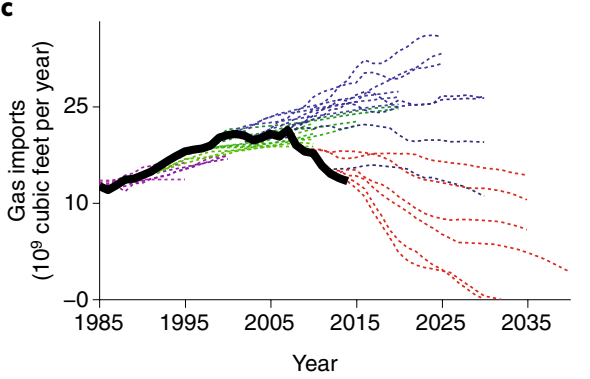

Corrected

a

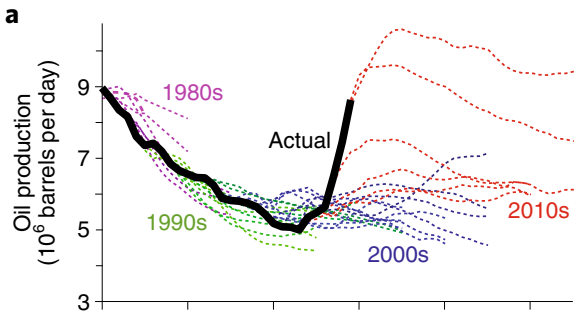

b

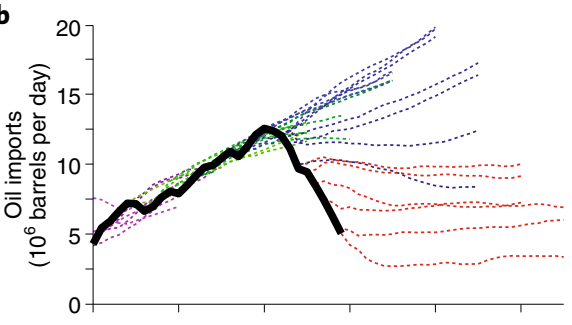

c

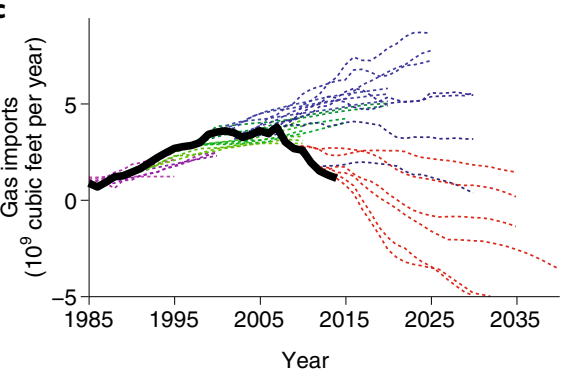

Fig. 1 | Original and corrected.

Published online: 3 May 2018

https://doi.org/10.1038/s41560-018-0149-5 